\title{
Leber Congenital Amaurosis
}

National Cancer Institute

\section{Source}

National Cancer Institute. Leber Congenital Amaurosis. NCI Thesaurus. Code C129075.

A congenital retinopathy that is associated with mutation(s) in at least eighteen genes, typically characterized by severe visual impairment. 